\title{
Acute appendicitis clinical presentation in patients immunocompromised by diabetes or HIVIAIDS
}

\author{
Guillermo Ponce de León-Ballesteros, Rafael Pérez-Soto, Karla Zúñiga-Posselt and \\ David Velázquez-Fernández \\ Secretaría de Salud, Instituto Nacional de Ciencias Médicas y Nutrición "Salvador Zubirán", Department of Surgery, Ciudad de México, Mexico
}

\begin{abstract}
Introduction: Immunocompromised patients experience limited inflammatory response, which can delay acute appendicitis (AA) diagnosis. Objective: To assess if immunosuppression can affect AA clinical course and evolution. Method: Comparative, retrospective analysis of patients with HIV or type 2 diabetes mellitus (DM2) or with no other pathology who underwent appendectomy for $A A$. Results: $A$ total of 128 patients with $A A$ who were surgically intervened were assessed (53.6\% were of the female gender); mean age was 42.5 years, 15 (11.7\%) had been diagnosed with HIV infection, 47 (36.7\%) with DM2 and 66 (51.6\%) had no other disease. The proportion of leukocytosis was lower in the HIV group (66.7\%; $p=0.007)$. Patients with HIV and DM2 had longer evolution time (HIV $66.9 \pm 61.2$, DM2 $90.1 \pm 144$ hours; $p \leq 0.001$ ), longer hospital length of stay (HIV $11.1 \pm 17.1$, DM2 $6.5 \pm 4.1$ days; $p \leq 0.0001$ ), and a higher rate of complications (HIV 20\%, DM2 23.8\%; $p=0.036$ ). The most common complication was superficial and deep surgical site infection. Right hemicolectomy was more common in the HIV group (20\%; $p=0.017)$. There was no mortality registered. Conclusions: Immunosuppression affects AA clinical course and evolution.
\end{abstract}

KEY WORDS: Acute appendicitis. HIV. Diabetes mellitus. Immunocompromised. Surgical complications.

\section{Introduction}

Acute appendicitis (AA) is the main surgical emergency in the world, and hence it constitutes an important health problem. The prevalence of acute appendicitis in the general population is $0.1 \%$ and the risk for suffering from it is $8 \%$, while in patients with human immunodeficiency virus/acquired immunodeficiency syndrome (HIV/AIDS) the prevalence ranges from 0.6 to $3.6 \% .^{1-3}$ In addition, the incidence of AA has increased in developing countries, probably owing to the increase of HIV/AIDS cases. ${ }^{1}$ AA-associated mortality has historically declined since its surgical treatment was described, from $26 \%$ to less than 0.2 per 100000 population currently. However, the presence of comorbidities and of complicated or perforated AA can increase mortality to up to $5 \%$. In patients with HIV/AIDS with complicated AA it can reach $22 \%{ }^{1}$
Some reports indicate that the higher incidence of $A A$ in patients with HIV/AIDS might be related to the fact that vermiform appendix is a target organ for the virus. ${ }^{2}$ In addition, up to $30 \%$ of clinical presentations in these patients are associated with any comorbidity, mainly infectious, as, for example, Kaposi's sarcoma, and cytomegalovirus, Mycobacterium sp., Cryptosporidiosis and Salmonella typhy infection, among others. ${ }^{3}$

Patients with HIV/AIDS who are diagnosed with AA are on average older than the general population. Some clinical differences of these patients when compared with controls without any other pathology than AA are a lower frequency of leukocytosis $(34.6 \%$ versus $87 \%$, respectively), lower frequency of fever (46.1 to $55 \%$ versus $66.5 \%$, respectively). ${ }^{1,3-5}$

A higher rate of perioperative complications has been reported in patients with HIV/AIDS, with the most common including surgical site infection, delay or
Correspondence:

Guillermo Ponce de León-Ballesteros

E-mail: guillermoplb @ hotmail.com
Date of reception: 03-11-2017

Date of acceptance: 11-12-2017

DOI://dx.doi.org/10.24875/GMM.M18000174
Gac Med Mex. 2018;154:399-404

Contents available at PubMed www.gacetamedicademexico.com 
alterations in the healing of the surgical wound, higher rate of complicated AA (perforated AA, generalized peritonitis, intra-abdominal abscess), longer hospital stay and higher mortality. ${ }^{1,3-5}$

Patients with HIV/AIDS have 15 -fold higher risk of acute perforated appendicitis than the general population, with this being the main predictor of mortality. ${ }^{6}$

As for type 2 diabetes mellitus (DM2), it is associated with a higher rate of complications. Poor control of the disease is related to most complications. Immunoglobulin glycosylation of is the main mechanism by means of which the immune system is affected, in addition to the fact that there is an alteration in polymorphonuclear cells function, leukocyte adherence and a decrease in chemotaxis and phagocytosis. ${ }^{7}$

Like patients with HIV/AIDS, patients with DM2 who are diagnosed with $A A$ are older than the general population, and also have a higher rate of complications, of complicated AA frequency and of hospital stay.

The higher complication rate can be associated with delayed diagnosis, alterations in the immune system or with the presence of comorbidities related to or triggered by HIV/AIDS and DM2.?

The complication rate is higher in the HIV/AIDS and DM2 groups in comparison with the general population, as already mentioned. The rate of complicated AA in patients with HIV/AIDS it 8 to $33 \%$, and in patients with DM2 it ranges from 22.6 to $64.8 \%$, while the figures reported for patients without other diseases range from 3.5 to $19 \%{ }^{1,5,7,8}$ Generalized peritonitis in patients with HIV/AIDS has been reported in up to $31 \%$, in diabetic patients in 18 to $22.6 \%{ }^{7-10}$ while in the general population in 2 to $8 \%$, and it is therefore concluded that these groups have up to 15 -fold higher risk for experiencing complicated AA.

The purpose of this study was to assess whether immunocompromise can affect the clinical course and evolution of patients with $A A$ in comparison with individuals without other diseases, in addition to comparing two different groups of patients with immunocompromise and $\mathrm{AA}$.

\section{Method}

Observational, retrospective study with comparative-correlational scope. It was carried out at Instituto Nacional de Nutrición y Ciencias Médicas "Salvador Zubirán", which is a tertiary care center in Mexico. Different variables were analyzed: age, gender, signs and symptoms, clinical and histopathological diagnosis, laboratory results, trans-operative findings, surgical technique and postoperative complications. Patients were older than 18 years and were distributed as follows: group with HIV (15 patients), group with DM2 (47 patients) and group of patients with apparently no condition other than AA (66 controls) and in whom there was no evidence of previous illness; all were surgically intervened for AA at Instituto Nacional de Nutrición y Ciencias Médicas "Salvador Zubirán" between 1990 and 2013. In the patients with HIV/AIDS, other variables such as antiretroviral treatment, classification of the disease based on the World Health Organization classification, viral load and CD4+ cell count at AA diagnosis were analyzed.

All patients with HIVIAIDS who underwent open or laparoscopic appendectomy in the aforementioned period were included; as for the control patients and those with DM2, the sample was obtained in a probabilistic and systematic form from the list of all patients operated for AA in the same period (833 patients), with at least a 3:1 ratio with regard to the patients with HIV. Patients diagnosed with type 1diabetes mellitus, hematological or solid neoplasms, autoimmune diseases, on pharmacological immunosuppression or with another type of immunocompromised were excluded.

The statistical analysis was carried out with the SPSS Statistics version 20.0 and Excel programs. Nonparametric statistical analysis was performed owing to the collected sample. For the comparison of the dimensional variables, Student's t test and ANOVA were used; for ordinal and categorical variables, Kendall's tau test and the chi-square, respectively, were used. A p-value $\leq 0.05$ or $5 \%$ ( $\alpha$ error) for a twotailed hypothesis test was considered to be statistically significant.

The protocol was reviewed and approved by the Institutional Committee of Biomedical Research in Humans (reference 1142).

\section{Results}

Of the 128 patients, 67 were men (53.6\%) and 58 were women $(46.4 \%)$, with an age of $42.5 \pm 15.8$ years, ranging from 18 to $91 ; 15$ (11.7\%) were diagnosed with HIV, $47(36.7 \%)$ with DM2 and 66 (51.6\%) were controls. The control group was significantly younger (33.67 years versus 39 years of patients with HIV versus 54.74 years in those with DM2, $p \leq 0.001$ ) (Fig. 1). In the group of patients with HIV, 13/15 (86.6\%, 


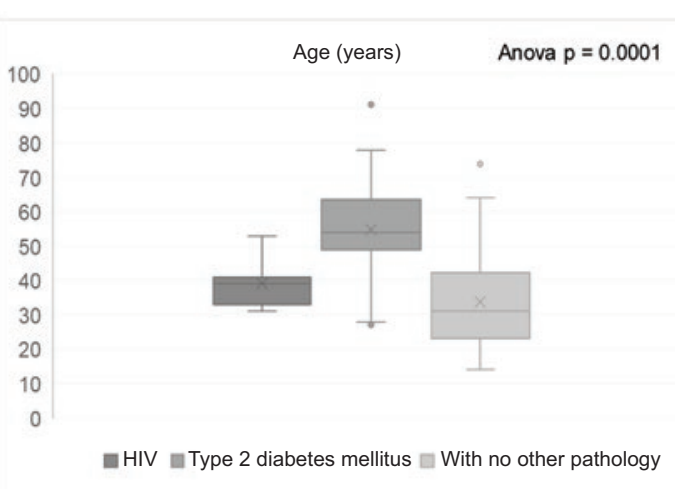

Figure 1. Groups' average age.

$p=0.007)$ were men, as well as $19 / 47(40.4 \%)$ in the DM2 group and 36/66 (54.5\%) in the control group.

All patients with HIV were found to be receiving antiretroviral therapy. As regards diseases associated with HIV/AIDS, one patient had been recently diagnosed with disseminated cytomegalovirus infection, and 3 had a history of pulmonary tuberculosis; however, in none of them could it be determined whether AA was related to these diagnoses. In one, the definitive histopathological report was carcinoid tumor of the appendix and in the rest, AA. Patients with lower CD4+ lymphocyte counts had lower frequency of leukocytosis in comparison with other patients in the group, with the difference not being statistically significant (ANOVA, $p=0.47$ ). Patients who did not develop leukocytosis were classified at stage 3 according to the World Health Organization classification owing to their current or previous CD4+ lymphocyte counts. Neither a detectable viral load nor the number of copies were correlated with any prognostic factor or complication (chi-square, $p=0.31$ ) (Table 1).

Demographic variants, as well as clinical and perioperative data in the different groups are described Tables 2 and 3 . The proportion of leukocytosis was lower in the HIV group: $66.7 \%$ versus $85.1 \%$ in the group with DM2 and $85.7 \%$ in the control group (chi-square, $p=0.007$ ), however, there was no difference between the DM2 and the control group $(p=0.9)$ (Fig. 2).

As for clinical presentation, a smaller proportion of patients with HIV experienced diffuse abdominal pain: $60 \%$ versus $83 \%$ in the group with DM2 and $89 \%$ in the control group (chi-square, $p=0.022$ ), as well as pain in the right iliac fossa: $80 \%$ versus $98 \%$ in the group with DM2 and $94 \%$ in the control (chi-square, $p=0.046$ ). Evolution time was superior in patients with HIV and DM2 in comparison with controls: $66.9 \pm 61.2$,

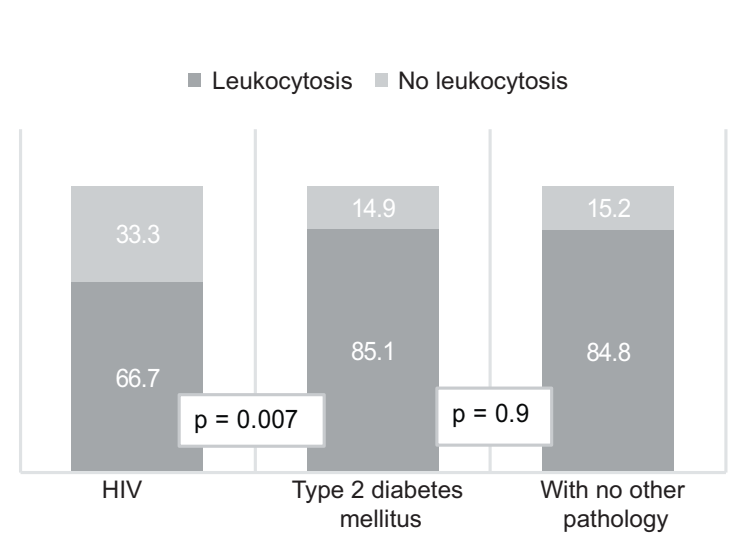

Figure 2. Leukocytosis proportion by group. Chi-square when comparing the control group with the groups with HIV and type 2 diabetes mellitus.

$90.1 \pm 144$ and $28 \pm 22.6$ hours, respectively (ANOVA, $p \leq 0.001$ ) (Fig. 3). A higher proportion of patients with HIV and DM2 had fever in relation to controls: 20, 27.7 and $11.3 \%$, respectively (chi-square, $p=0.09$ ), without the difference reaching significance.

The presentation of complicated AA was more common in the group with DM2: $50 \%$ versus $26.7 \%$ in the group with HIV and $27.3 \%$ in the control group (chi-square, $p=0.004$ ), as well as the presence of intra-abdominal abscess: $39.1 \%$ versus $20 \%$ in the HIV group and $9 \%$ in the control group (chi-square, $p=0.001$ ); however, perforated AA showed no difference between groups, in spite of being more common in the control group: $18.2 \%$ versus $6.7 \%$ in the HIV group and $10.9 \%$ in the group with DM2 (chi-square, $p=0.37$ ) (Fig. 4). Of the patients with HIV, $26 \%$ were classified as having complicated AA: 3 patients with intra-abdominal abscess and one with perforated AA.

The laparoscopic approach was more frequently used in the control group, with the difference being significant: $36.4 \%$ versus $13.3 \%$ in the group with HIV and $13 \%$ in the group with DM2 (chi-square, $p=0.011)$. In one patient in the HIV group $(6.7 \%)$, the laparoscopic approach had to be converted to an open appendectomy, as well as in $5(10.9 \%)$ of the group with DM2 and in $2(3 \%)$ of the controls (chisquare, $p=0.24$ ). Figure 5 shows the percentages of type of approach used in the groups. The need to perform right hemicolectomy was greater for the group with HIV, with regard the other groups: $20 \%$ versus $6.3 \%$ in the group with DM2 and $1.5 \%$ in the control group (chi-square, $p=0.017$ ).

The right hemicolectomy indication in two patients (13.3\%) of the HIV group was for intraabdominal abscess and involvement of the base of the vermiform appendix and in one $(6.6 \%)$ due to a suspected tumor, 
Table 1. Characteristics of the patients with HIV and acute appendicitis

\begin{tabular}{|c|c|c|c|c|c|c|c|c|c|c|c|}
\hline Patient & $\begin{array}{l}\text { WHO } \\
\text { classification }\end{array}$ & $\begin{array}{l}\text { Viral } \\
\text { load }\end{array}$ & CD4+ & $\begin{array}{l}\text { Leukocytes } \\
\text { prior to AA }\end{array}$ & $\begin{array}{l}\text { AA } \\
\text { leukocytes }\end{array}$ & Comorbidities & $\begin{array}{l}\text { Trans-operative } \\
\text { finding }\end{array}$ & Hemicolectomy & $\begin{array}{l}\text { Hospital } \\
\text { stay (days) }\end{array}$ & Complicat & ations \\
\hline 1 & A2 & - & 366 & ND & 19600 & - & $\begin{array}{l}\text { Intra-abdominal } \\
\text { abscess }\end{array}$ & Yes & 4 & \multirow[t]{4}{*}{ Bleeding } & $g \gg 500 \mathrm{~mL}$ \\
\hline 2 & A3 & - & 577 & 6800 & 18200 & - & $A A$ & - & 2 & & हे \\
\hline 3 & $\mathrm{~A} 1$ & - & 761 & 6200 & 14500 & - & AA & - & 2 & & $\frac{5}{1}$ \\
\hline 4 & A3 & - & 337 & 5300 & 8600 & CMV & AA & - & 2 & & (C) \\
\hline 5 & A3 & - & 180 & 4600 & 10900 & - & $\begin{array}{l}\text { Perforated } \\
\text { appendix }\end{array}$ & - & 9 & \multirow[t]{5}{*}{ SSI } & $\dot{\oplus}$ \\
\hline 6 & A2 & 14700 & 283 & 3900 & 11100 & MTb & AA & - & 5 & & $\underline{\bar{n}}$ \\
\hline 7 & C3 & - & 65 & 2100 & 3300 & - & AA & - & 67 & & 음 \\
\hline 8 & A2 & - & 633 & 7800 & 12200 & - & AA & - & 5 & & 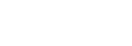 \\
\hline 9 & C3 & - & 565 & ND & 17500 & - & AA & - & 2 & & 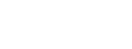 \\
\hline 10 & $\mathrm{~A} 2$ & - & 764 & 7000 & 19730 & - & $\begin{array}{l}\text { Intra-abdominal } \\
\text { abscess }\end{array}$ & - & 30 & \multicolumn{2}{|c|}{ Re-operation } \\
\hline 11 & A2 & 51627 & 308 & 5100 & 18700 & - & AA & - & 3 & & 气 \\
\hline 12 & C3 & - & 423 & 5000 & 14800 & - & AA & - & 3 & & \pm \\
\hline 13 & C3 & 78 & 441 & 5200 & 6500 & - & $\begin{array}{l}\text { AA } \\
\text { Carcinoid tumor }\end{array}$ & Yes & 13 & & $\frac{1}{\circ}$ \\
\hline 14 & C3 & - & 329 & 5200 & 8000 & MTb & $\begin{array}{l}\text { Intra-abdominal } \\
\text { abscess }\end{array}$ & Yes & 6 & \multirow[t]{2}{*}{ Bleeding } & $1200 \mathrm{~mL}$ \\
\hline 15 & C3 & 2500 & 99 & 3200 & 2100 & MTb & AA & - & 13 & & ○ \\
\hline
\end{tabular}

$\mathrm{AA}=$ Apendicitis aguda, $\mathrm{CMV}=$ Citomegalovirus, $\mathrm{MTb}=$ Mycobacterium tuberculosis, ISQ=Infección de sitio quirúrgico

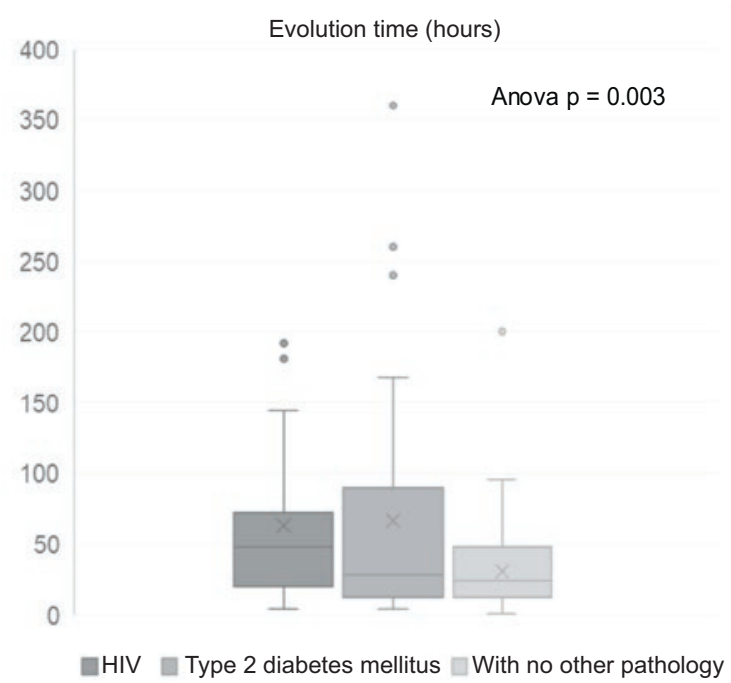

Figure 3. Clinical symptoms evolution time by group.

where histopathological diagnosis was appendicular carcinoid tumor. Right hemicolectomy was performed for an abscessed mass in the group with DM2, while in the only patient who required it in the control group it was due to important involvement of the caecum. Surgical time was also significantly longer for the group

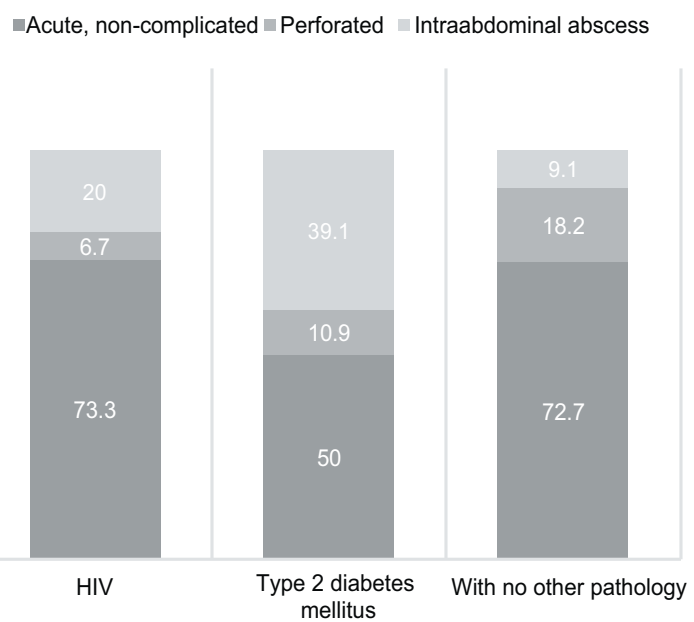

Figure 4. Proportion of non-complicated and complicated (perforated/ intraabdominal abscess) acute appendicitis by group.

with HIV: 112.9 minutes versus 99.4 in the group with DM2 and 77.7 in the control group (ANOVA, $p=0.037$ ) (Fig. 6), as well as intraoperative bleeding, with the difference being statistically significant: $214.2 \pm 364.4 \mathrm{~mL}$ versus $162.02 \pm 254.9$ and $33 \pm 29.3 \mathrm{~mL}$ in the DM2 and control groups, respectively (ANOVA, $p=0.001$ ). 
Table 2. Description of demographic and clinical characteristics of patients with acute appendicitis

\begin{tabular}{lcccc}
\hline Characteristic & $\begin{array}{c}\text { Group 1 } \\
\text { HIVIAIDS }\end{array}$ & $\begin{array}{c}\text { Group 2 } \\
\text { DM2 }\end{array}$ & $\begin{array}{c}\text { Group 3 } \\
\text { Control }\end{array}$ & $\mathbf{p}$ \\
\hline Age (years) & 39 & 54.74 & 33.67 & $\leq 0.001$ \\
Leukocytosis (\%) & 66.7 & 85.1 & 85.7 & 0.007 \\
Fever (\%) & 20 & 27.7 & 11.3 & 0.09 \\
Evolution time (hours) & 66.87 & 90.07 & 28 & 0.001 \\
RIF pain (\%) & 80 & 98 & 94 & 0.046 \\
Diffuse abdominal pain (\%) & 60 & 83 & 89 & 0.022 \\
Rebound (\%) & 73 & 83 & 77 & 0.64 \\
Pain migration (\%) & 60 & 68 & 75 & 0.43 \\
Nausea (\%) & 80 & 74 & 86 & 0.3 \\
Vomiting (\%) & 60 & 45 & 62 & 0.19 \\
Hyporexia (\%) & 100 & 81 & 84 & 0.19 \\
Alvarado scale (mean) & 7.13 & 7.87 & 7.63 & 0.32 \\
\hline
\end{tabular}

Table 3. Description of perioperative characteristics of patients with acute appendicitis

\begin{tabular}{lcccc}
\hline \multicolumn{1}{c}{ Characteristic } & $\begin{array}{c}\text { Group } \\
\text { HIVI } \\
\text { AIDS }\end{array}$ & $\begin{array}{c}\text { Group } \\
\mathbf{2} \\
\text { DM2 }\end{array}$ & $\begin{array}{c}\text { Group } \\
\mathbf{3} \\
\text { Healthy }\end{array}$ & p \\
\hline Non-complicated AA (\%) & 73.3 & 50 & 72.7 & 0.035 \\
Perforated AA (\%) & 6.7 & 10.9 & 18.2 & 0.37 \\
Intraabdominal abscess (\%) & 20 & 39.1 & 9 & 0.001 \\
Surgical time (minutes) & 112.86 & 99.37 & 77.7 & 0.037 \\
Right hemicolectomy (\%) & 20 & 6.3 & 1.5 & 0.016 \\
Bleeding (mL) & 214.17 & 162.02 & 33 & 0.001 \\
Transfusion (\%) & 20 & 6.7 & 2 & 0.021 \\
Reoperation (\%) & 6.7 & 0 & 0 & 0.025 \\
Hospital stay (days) & 11.07 & 6.47 & 3.3 & $\leq 0.0001$ \\
Complications (\%) & 20 & 23.8 & 4.8 & 0.036 \\
\hline
\end{tabular}

The proportion of postoperative complications was higher in the groups with HIV and DM2: 20 and $23.8 \%$, respectively, versus $4.8 \%$ in the control group (chi-square, $p=0.036$ ). All patients in the group with HIV had an infection of the superficial surgical site; in the group with DM2, $4(8.6 \%)$ had intraabdominal abscess, and 7 (14.9\%), infection of the superficial surgical site. In the control group, 2 patients (3\%) experienced surgical site superficial infection and one (1.5\%), intra-abdominal abscess. The groups with HIV and DM2 had longer hospital stay: $11.1 \pm 17.1$ and $6.5 \pm 4.1$ days, respectively, versus $3.2 \pm 4.1$ days in

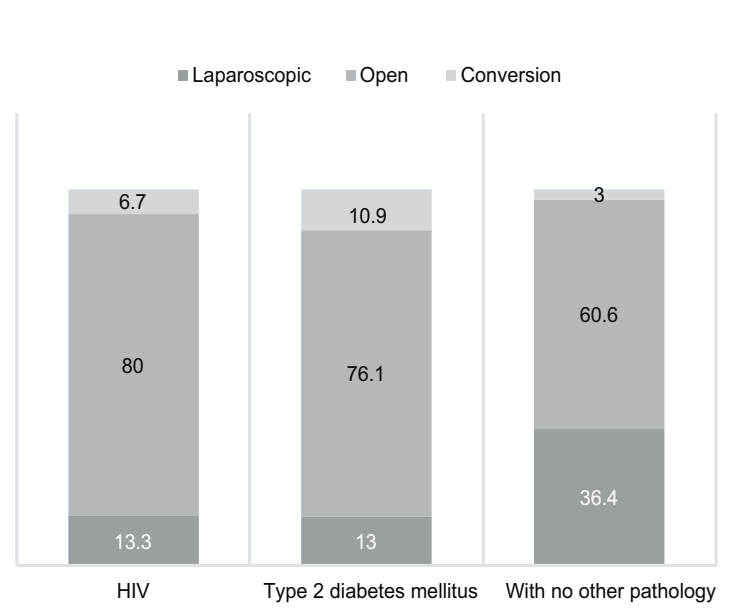

Figure 5. Proportion of surgical approaches employed and conversion by group.

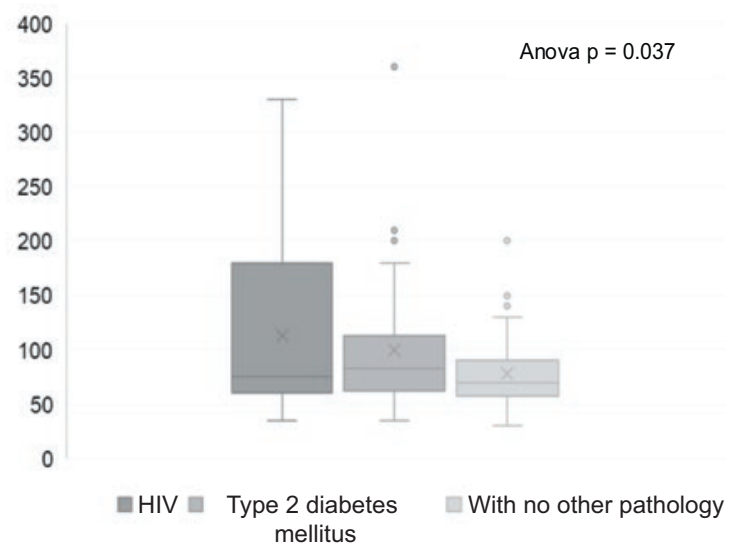

Figure 6. Surgical time in minutes by groups.

the control group (ANOVA, $p \leq 0.0001$ ). There was no mortality recorded in any of the groups. The posthoc analysis comparing the percentage of complications in the groups with HIV and DM2 showed a $\beta$ power of $83.9 \%$ and an $\alpha$ error of 0.05 .

\section{Discussion}

Our study demonstrated that patients with HIV and DM2 were older, which is consistent with findings described in other studies. ${ }^{1,7}$

As for clinical presentation, the two study groups showed a longer evolution time; patients with HIV had a lower proportion of diffuse abdominal and right iliac fossa (RIF) pain and lower frequency of leukocytosis $(66.7 \%)$. In previous studies where patients with HIV/AIDS and patients without any pathology other than AA were compared, the latter experienced leukocytosis more frequently: $87 \%$ versus 34.6 and $88 \%$, as well as fever: $66.5 \%$ versus 46.1 and $55 \% .^{1.4 .5}$ 
In our series, patients with HIV had higher proportion of fever that the control group, with the difference not being statistically significant. Other clinical data such as pain migration, anorexia, nausea, vomiting and rebound were not significant in terms of frequency of presentation, just as reported by Gliti et al. ${ }^{1}$

In patients with DM2, a higher proportion of complicated AA (50\%) was observed, whereas in the group with HIV the percentage was similar to that in the control group (25.6 and $27.3 \%$, respectively); howev$\mathrm{er}$, a higher percentage of patients with HIV required right hemicolectomy $(20 \%)$. The high frequency of complicated AA in the control group did not agree with that reported in other series, probably owing to the fact that the place where the study was carried out is a tertiary care center and patients usually have complications. Of the patients with DM2 who had complicated $\mathrm{AA}$, in $39.1 \%$ it was by intraabdominal abscess, and in $10.9 \%$, AA by perforation, while $20 \%$ of patients with HIV had intraabdominal abscess, and $5.6 \%$, perforated AA.

In 2008, Tsai et al. compared 71 patients with DM2 that developed AA versus patients without DM2 and $\mathrm{AA}$; the former had higher risk of AA-related complications, longer time of stay $(11 \pm 1.1$ days versus 4.4 \pm 0.1 days, $p=0.001$ ) and higher proportion of complicated AA (64.8\%). The higher rate of complications can be related to delayed diagnosis, immune system alterations or to the presence of DM2-related comorbidities (micro or macrovascular disease and nephropathy). ${ }^{7}$ Our findings in patients with HIV were correlated with those observed in other series, where a rate of complicated AA from 8 to $33 \%$ has been reported, and even a 15 -fold higher risk of perforated AA than in the general population has been reported. ${ }^{15,8}$

Patients with HIV and DM2 showed more postoperative complications (surgical site superficial infection, intraabdominal abscess), as well as longer surgical time and hospital stay. Up to $11.5 \%$ of patients with HIV have been reported to experience surgical site infection, which is a higher proportion than that in the general population, where it is 2 to $4 \%$; in our series it was 20 $\% .{ }^{1}$ In diabetic patients, a higher proportion of surgical site infection has also been described: Sivrikos et al. recorded $6.1 \%$; in our group with DM2 it was 14.9 and $8.6 \%$ for infection to organs and spaces. ${ }^{10}$

Regarding hospital length of stay, in patients with HIV, an average of 4.4 to 9.3 days has been reported, which is longer than in the general population. ${ }^{4,5}$ It is not different for patients with DM2, in whom it is described to range from 2.5 to 11 days, in addition to being longer for complicated AA cases (4 to 11 days). ${ }^{7,10}$ In our series, hospital length of stay for the HIVIAIDS, DM2 and control groups was $11,6.47$ and 3.24 days, respectively, which is similar to that described in the literature.

Our study had various limitations owing to the fact that it was retrospective and that it was carried out in a single center and with a small sample of patients with HIV; however, in the post-hoc analysis comparing the percentage of complications observed in the groups with HIV and DM2, a $\beta$ power of $83.9 \%$ with an $\alpha$ error of 0.05 was obtained.

\section{Conclusions}

Patients with HIV or DM2 with AA showed longer evolution time, which implied a diagnostic delay, more frequent postoperative complications and longer hospital stay in comparison with the subjects of the control group. The most common complication was surgical site infection. Immunosuppression affects AA patients' clinical course and evolution. Careful and early evaluation and opportune surgical treatment can reduce the higher frequency of complications.

\section{References}

1. Giiti G, Mazigo H, Heukelbach J, Mahalu W. HIV, appendectomy and postoperative complications at a reference hospital in Northwest Tanzania: cross-sectional study. AIDS Res Ther. 2010;7:47.

2. Mueller GP, Williams RA. Surgical infections in AIDS patients. Am J Surg. 1995;169:34S-38S.

3. Crum-Cianflone N, Weekes J, Bavaro M. Appendicitis in HIV-infected patients during the era of highly active antiretroviral therapy. HIV Med. 2008;9:421-426.

4. Whitney TM, Macho JR, Russell TR, Bossart KJ, Heer FW, Schecter WP. Appendicitis in acquired inmmunodeficiency syndrome. Am J Surg. 1992;164:467-470.

5. Liu K, Shyu J, Uen YH, Chen TH, Shyr YM, Su CH, et al. Acute apendicitis in patients with acquired immunodeficiency syndrome. J Chin Med Assoc. 2005;68:226-229.

6. Cooperman M. Complication of appendectomy. Surg Clin North Am. 1983;63:1233-1247.

7. Tsai S, Hsu C, Chen S, Lin YY, Chu SJ. Complicated acute appendicitis in diabetic patients. Am J Surg. 2008;196:34-39.

8. Salzman DJ, Williams RA, Gelfand DV, Wilson SE. The surgeon and AIDS: twenty years later. Arch Surg. 2005;140:961-967.

9. Aldeen T, Horgan M, Macallan DC, Thomas V, Hay P. Is acute appendicitis another inflammatory condition associated with highly active antiretroviral therapy (HAART)? HIV Med. 2000;10:252-255.

10. Sivrikoz E, Karamanos E, Beale E, Teixeira $P$, Inaba K, Demetriades D. The effect of diabetes on outcomes following emergency appendectomy in patients without comorbidities: a propensity score-matched analysis of National Surgical Quality Improvement Program database. Am J Surg. 2015;209:206-211. 